\title{
Laparoscopic pancreaticoduodenectomy: are the best times coming?
}

\author{
Mengqi Liu ${ }^{1,2,3}$, Shunrong Ji, ${ }^{1,2,3}$, Wenyan $X u^{1,2,3}$, Wensheng Liu ${ }^{1,2,3}$, Yi Qin ${ }^{1,2,3}$, Qiangsheng $\mathrm{Hu}^{1,2,3}$, Qiqing Sun ${ }^{1,2,3}$, \\ Zheng Zhang ${ }^{1,2,3}$, Xianjun $Y_{u^{1,2,3^{*}}}$ (i) and Xiaowu Xu ${ }^{1,2,3^{*}}$
}

\begin{abstract}
Background: The introduction of laparoscopic technology has greatly promoted the development of surgery, and the trend of minimally invasive surgery is becoming more and more obvious. However, there is no consensus as to whether laparoscopic pancreaticoduodenectomy (LPD) should be performed routinely.

Main body: We summarized the development of laparoscopic pancreaticoduodenectomy (LPD) in recent years by comparing with open pancreaticoduodenectomy (OPD) and robotic pancreaticoduodenectomy (RPD) and evaluated its feasibility, perioperative, and long-term outcomes including operation time, length of hospital stay, estimated blood loss, and overall survival. Then, several relevant issues and challenges were discussed in depth.

Conclusion: The perioperative and long-term outcomes of LPD are no worse and even better in length of hospital stay and estimated blood loss than OPD and RPD except for a few reports. Though with strict control of indications, standardized training, and learning, ensuring safety and reducing cost are still and will always the keys to the healthy development of LPD; the best times for it are coming.
\end{abstract}

Keywords: Laparoscopic, Pancreaticoduodenectomy, Open surgery, Robotic, Overall survival

\section{Background}

The introduction of laparoscopic techniques in the 1980s heralded the start of revolutions in general surgical procedures and was performed in almost every abdominal surgery. Mounts of clinical trials were designed to provide evidence of laparoscopic safety and efficacy to inform clinical practices. Most studies comparing laparoscopy to traditional laparotomy have shown that laparoscopically resected patients experience less blood loss, postoperative pain and morbidity, shorter length of stay, improved cosmesis, and enhanced cost-effectiveness in multitude fields, including gastric, liver, and colon cancers[1-3]. Then, the last decade has seen the introduction of robotic assistance and more recently its application in many kinds of operations. Laparoscopic approaches to pancreatic surgery have not been widely adopted as the case in colorectal, urological, and gynecological surgeries, and almost all of laparoscopic

\footnotetext{
* Correspondence: yuxianjun@fudanpci.org; xuxiaowu@fudanpci.org M. Liu and S Ji contributed equally to this article.

1 Department of Pancreatic Surgery, Fudan University Shanghai Cancer Center, Shanghai 200032, China

Full list of author information is available at the end of the article
}

pancreatic surgeries were performed in large, tertiary care centers. Though laparoscopy has been introduced in the field of pancreatic surgery for several decades, it mainly focused on the treatment of pancreatitis with pseudo-pancreatic cysts, laparoscopic exploration to assist pancreatic cancer staging, and advanced pancreatic tumors for palliative surgery and resection, etc. $[4,5]$. While in the traditional sense of pancreatic surgery, such as operations like distal pancreatectomy, especially pancreaticoduodenectomy, it had been monopolized by open surgery, because of the multiple anastomoses reconstructions and large specimens during the operation, as well as because of concern for the potential for significant perioperative complications or death and the concern about adequate oncological outcomes when it is performed for malignant diseases [6].

However, after several decades of development, with the gradual deepening of the understanding of the anatomy of the pancreas, the emergence of a series of new surgical instruments, the application for laparoscopic pancreatic resection has been greatly broadened. Both laparoscopic distal pancreatectomy (LDP) and laparoscopic pancreaticoduodenectomy (LPD) are being performed more and 
more in the procedures of pancreatic surgery. And so far, LDP has already been widely adopted for benign and borderline tumors of the left pancreas, and meta-analysis shows that the minimally invasive advantage of LDP is obvious [7]. Many believe this approach can be the standard of care for benign and borderline tumors, even at an early stage of malignant tumors in the tail of the pancreas. However, there is no consensus as to whether LPD, which is a much more complex procedure, should be performed routinely. Herein, in this review, we summarized the development of LPD in recent years by comparing the mean operative time, estimated blood loss, length of hospital stay, and overall survival with open pancreaticoduodenectomy (OPD) and robotic pancreaticoduodenectomy (RPD) and evaluated its feasibility, perioperative, and long-term results.

\section{Main text}

The Preferred Reporting Items for Systematic Reviews and Meta-Analyses (PRISMA) were used in this review. A literature search was performed in the PubMed and Web of Science. The keywords were combined using Boolean operators as follows: ( Laparoscopic [Title] AND Pancreaticoduodenectomy [Title] ) AND ( Robotic [Title] AND Pancreaticoduodenectomy [Title] ). Inclusion criteria were studies comparing the perioperative and/or postoperative outcomes of LPD and OPD/RPD published between January 1, 2001, and December 31, 2018. Exclusion criteria were case reports, review articles, meta-analysis, studies comparing OPD and RPD only, and studies focusing on the cost or other non-medical issues (Fig. 1).
Pancreaticoduodenectomy: laparoscopic versus open

Pancreaticoduodenectomy (PD), one of the subtlest and most complicated abdominal surgeries popularized by Whipple in 1935 [8], is the unique potential curative option for pancreatic cancer or periampullary malignancy. While for pancreatic cancer, apart from its deep location, even in the early stages, tends to metastasize and is more likely to invade its surrounding tissues or even major vessels around it. Therefore, PD was a surgery with high morbidity and mortality rate even in high-volume surgical institutions in the past. With the improvements in surgical techniques and perioperative care, significant advances have been achieved in PD over the past several decades and were widely accepted and performed on patients all around the world. In 1994, Gagner and Pomp first introduced laparoscopy to this most challenging operation [9]. Then, in 2007, Palanivelu et al. presented the first large series of LPD and proposed that not only was it possible but there may also be advantages in comparison to OPD in properly selected patients [10]. In 2011, a review of 27 published articles regarding LPD showed similar results with respect to perioperative morbidity and mortality rates compared to OPD [11]. Furthermore, several case series reported oncologic outcomes comparable to OPD in terms of consistent negative margin resection rates and lymph node retrieval [11-13]. A recent report analyzed 22,013 patients who underwent OPD or MIPD for pancreatic cancer using the National Cancer Database between 2010 and 2015, among which 3205 patients underwent LPD, and concluded that there was no difference in 90-day mortality

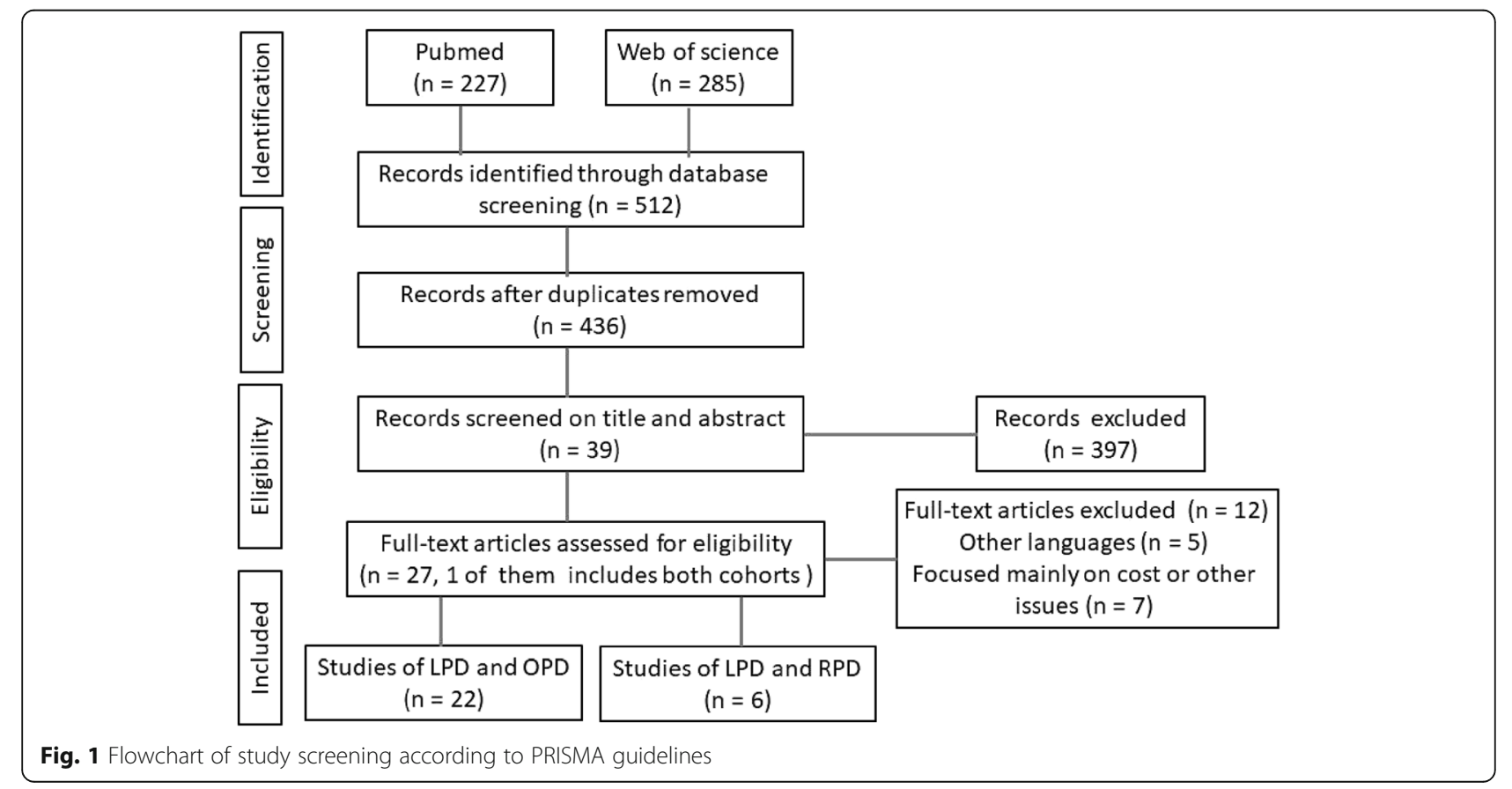


between LPD and OPD, and the 30-day mortality, unplanned readmissions, margins, lymph nodes harvested, and receipt of adjuvant chemotherapy were equivalent between groups. Patients undergoing LPD were less likely to stay in the hospital for a prolonged time [14]. Meng et al. found that compared with patients who underwent OPD, patients who underwent LPD had a shorter time to first passage of flatus and oral intake, while no differences were seen in blood loss, length of intensive care unit stay, node positive, or R0 resection between the laparoscopic and open groups, and concluded that LPD may be a preferred method for surgeons to choose compared with OPD [15]. Lee and colleagues compared the perioperative outcomes of LPD and OPD after propensity score matching of 31 patients with benign and borderline malignant periampullary disease in each group and concluded that LPD shortened the length of hospitalization stay and minimized pain, with less blood loss during the operation in patients undergoing LPD than in those undergoing OPD, while no significant differences about major complications including the rate of postoperative pancreatic fistula [16]. More comparisons between LPD and OPD are listed in Table 1 [15-36].

\section{Pancreaticoduodenectomy: laparoscopic versus robotic}

Since Himpens et al. introduced the first robotic surgery in cholecystectomy in 1997, the da Vinci robot had been applied in many surgical specialties such as gynecology and general surgery [37, 38]. However, until in 2010, the first manuscript report describing robotic pancreaticoduodenectomy was published by Giulianotti et al. [39], and then Nguyen and colleagues reported their experiences of the University of Pittsburgh [40]; both concluded that RPD/RAPD was safe and feasible if implemented reasonably. This opened the prelude to RPD; more and more centers carried out this procedure not only in benign disease processes and/or low-grade neoplasms but also in pancreatic cancer and periampullary malignancies and reported their data [41-44]. According to a recent report, Magge et al. found in a large series of RPD that the rate of postpancreatectomy hemorrhage (PPH), one of the most serious and life-threatening complications following PD, was similar to reported rates in historical open control series and pseudoaneurysm was less common with increasing experience [45]. In a subgroup analysis performed to compare outcomes following LPD versus RPD, the authors found there was no difference between LPD and RPD for short-term and oncologic outcomes, including operative time, estimated blood loss (EBL), length of postoperative hospital stay (LOS), and complication morbidities, but the rate of conversion from LPD to open is higher than RPD [14]. In another study comparing RPD and LPD using the pancreas-targeted American College of Surgeons National Surgical Quality Improvement Program (ACS-NSQIP),
Nassour and colleagues [6] also concluded RPD was associated with a lower rate of conversion than LPD and a similar 30-day overall complication rate. However, there is also a study that reports that no obvious differences in the conversion rate between LPD (7\%) and RAPD (8\%) were seen [46]. Zhang et al. reviewed 20 RPD and 80 LPD performed in their institution and concluded that RPD and LPD had comparable short term results, but they found RPD seems to have a shorter learning curve than LPD for this complex procedure [47]. More comparisons between LPD and OPD are listed in Table 2 [6, 14, 28, 47-49].

While at present, most studies are accustomed to combining LPD and RPD as MIPD, and then compare MIPD with OPD, thus drawing conclusions that MIPD is superior to OPD in some aspects, or compare RPD/ RAPD with OPD and draw conclusions [50-54]. Studies directly comparing robotic and laparoscopic approaches and concluding objective evidence of the advantages/disadvantages of the RPD over LPD are still lacking.

\section{Discussion}

As more and more laparoscopic pancreatic surgeries being performed, encouraging data has emerged. With the help of new surgical equipment, laparoscopic surgeons become more skilled and gain more experiences, and patients are being benefited by this expanding technology. After decades of development, there is no doubt that the technique is now mature and the operation is safe and reliable. However, the main concern of doctors and patients remains whether LPD can achieve similar oncology outcomes as OPD, including progression-free survival and overall survival.

To date, in the largest cohort study with 22,013 patients using a nationwide database to compare OPD and MIPD, Robert et al. demonstrate that LPD is to be equivalent to OPD with regards to oncologic outcomes of margin status and lymph nodes removed [14]. This is in consistence with the conclusion of Adam et al. who used NCDB data and reported equivalent oncologic outcomes in patients undergoing OPD versus LPD for adenocarcinoma [33]. In the study of a large series of total LPD performed at the Mayo Clinic, Croome et al. compared the oncologic outcomes of 108 LPD with 214 OPD, performed for pancreatic adenocarcinoma, and found patients who underwent LPD had longer progression-free survival than patients who had OPD [21]. Given the previous reports that there is a decrease in survival with increasing time interval to adjuvant chemotherapy in patients with colon cancer and ovarian cancer $[55,56]$, and the fact that a significantly smaller proportion of patients received adjuvant chemotherapy after surgery until more than 8 weeks in the LPD group than OPD group, the authors suggested that the survival differences may be related to the ability to initiate or complete chemotherapy which is of great value 


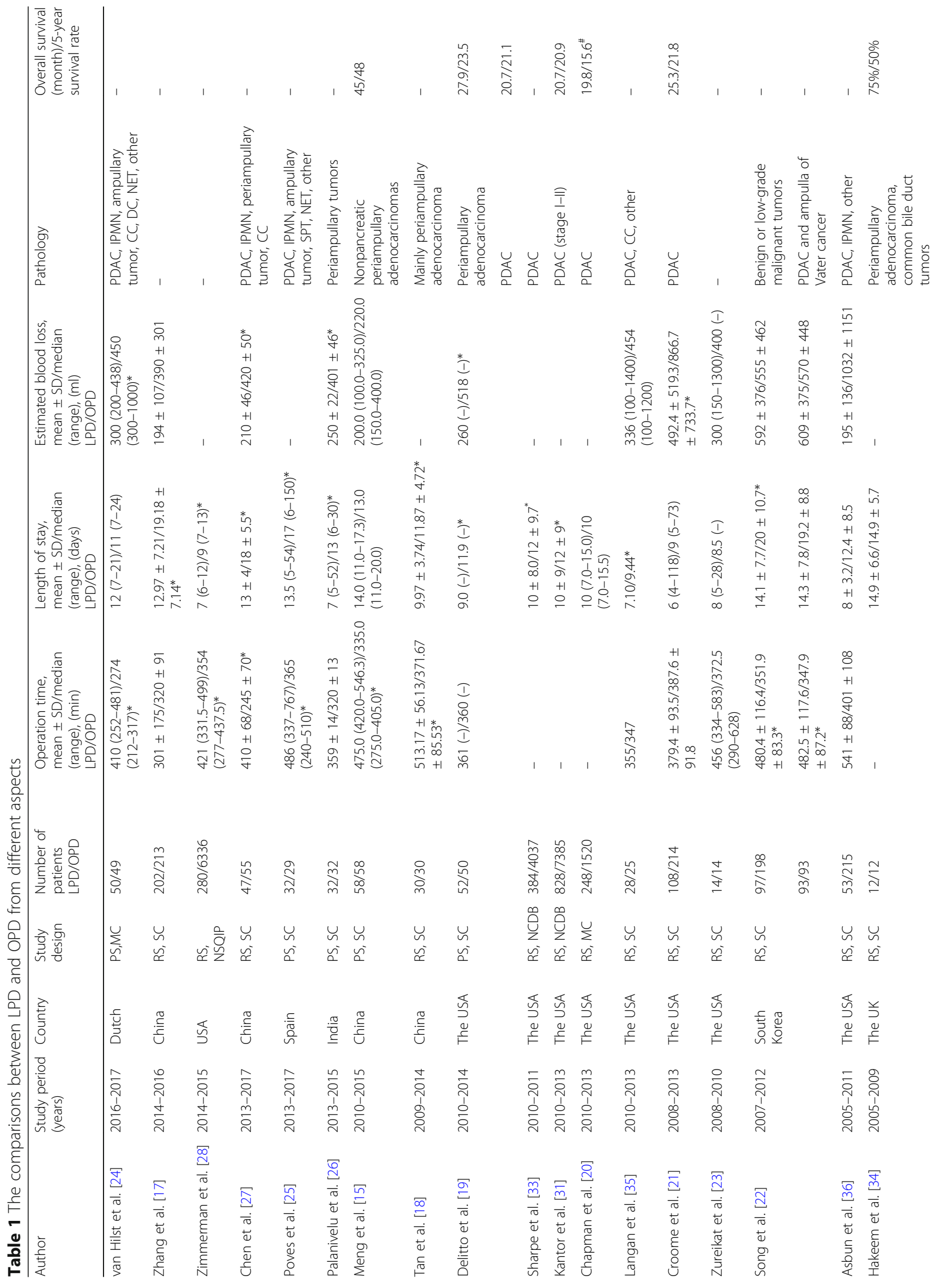


Lin et al. World Journal of Surgical Oncology

(2019) 17:81

Page 5 of 11

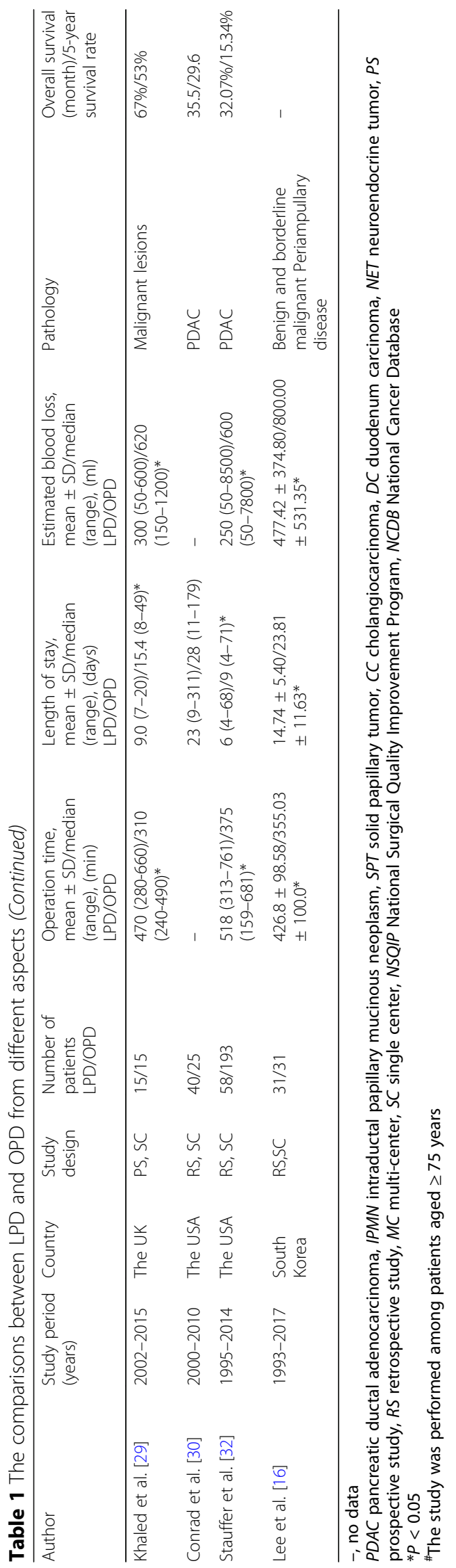




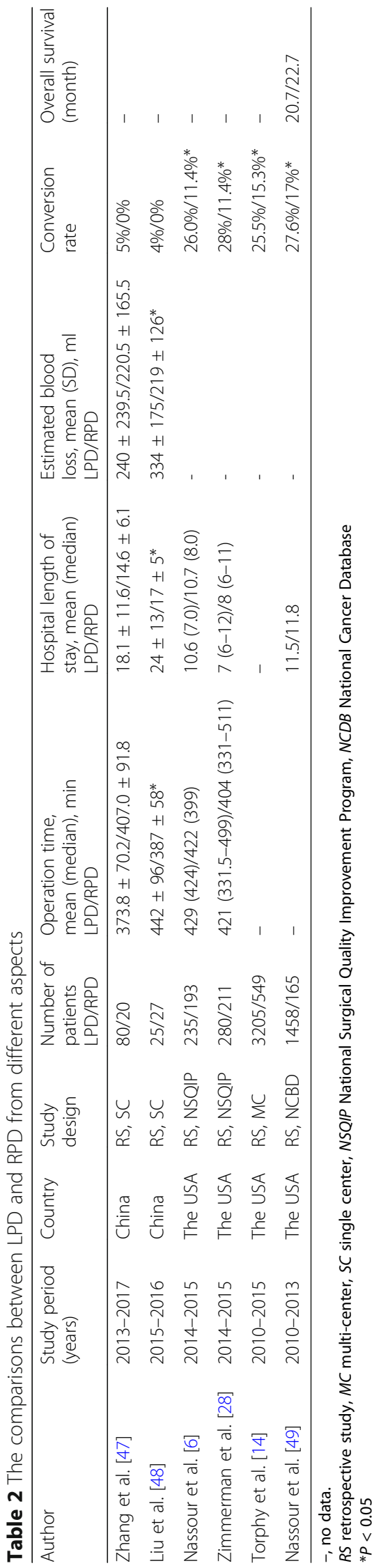


to the oncologic outcome of the patients with malignant tumors. Also owing to the improved magnification and optics offered by the laparoscopic system, LPD allows surgeons to more precisely and accurately locate, control, and even dissect both small vessels and SMVs to prevent massive bleeding, thus leading to less blood loss during the operation and lowering transfusion rate. Considering that intraoperative blood transfusion is associated with tumor recurrence and metastasis, this may be another benefit to the oncologic outcomes of LPD [57]. Apart from those, it has also been shown in the reports that open surgery with huge traumatic stress suppresses the immune system by multiple mechanisms, and these effects appear to be much reduced with laparoscopy [58]. Considering the close relationship between immune dysfunction and tumor recurrence and metastasis [59], this may be also an oncologic advantage of LPD. Nevertheless, large prospective randomized controlled trials are still needed to further confirm the conclusion and the reasons remain to be substantiated.

In addition to the oncology results of LPD which we concern the most, there are some other benefits. For example, some authors believe that the less manipulation required by the laparoscopic surgery may be related to the reduced occurrence of postoperative adhesion and delayed gastric emptying (DGE). LPD can also have advantages for the postoperative combined use of enhanced recovery after surgery (ERAS) which was popular in recent years to facilitate faster recovery by virtue of lower rate of postoperative complications and minimally invasive. It has been reported that laparoscopic surgery within an ERAS protocol leads to better immunity preservation after surgery in colon carcinoma patients [60]. There are no similar reports on PD so far; large randomized controlled clinical trials about this should be performed in the future. And to eliminate the selection bias for the LPD group, the comparison between LPD an OPD should be performed only in patients who are suitable for the ERAS program.

The issue of cost is often considered to be an obstacle in the adoption of LPD because of the higher expenditure during the operation. However, Gerber et al. found the cost of LPD was equivalent to OPD in a study, and the total episode-of-care cost was even lower than OPD [61]. Tran et al. also showed that LPD was associated with a reduction in hospital costs in high-volume pancreatic centers in comparison with OPD [62]. This may be mainly due to a shorter length of hospital stay and less intensive ward costs. Therefore, though the current milieu of healthcare reform mandates better surgical performance and more accountability, the value of complex surgical procedures depends on outcomes achieved per dollar spent, and these studies show that cost should not be the problem for LPD.

Robotic surgery has gained tremendous attention because it has the potential to overcome many limitations of conventional laparoscopy, such as limited movement, unnatural positions for the surgeons, and so on [63]. However, despite some studies reported that the encouraging outcomes of robotic surgeries, comparisons between robotic and laparoscopic pancreatic surgery techniques and outcomes are lacking, and prospective randomized controlled trials are needed to further clearly define this issue. Considering that patients who have a conversion to laparotomy, no matter during LPD or RPD, have a poorer prognosis than totally LPD or $\mathrm{RPD}$, it seems that this is an important merit of RPD compared with LPD according to some reports, but we should note this may mainly due to the high selective bias of the patients who underwent RPD considering the limited patients in the studies. The lack of tactile feedback seems to be a problem compared with laparoscopic surgery. Difficulties can arise during procedures with large operative fields such as PD, because they require changes of patients and instrument positions for retraction or exposure. The longer times for the robotic cases were anticipated given the additional time required to dock the robot, to exchange instruments, as well as to reposition or redock the instruments, if the viewing field necessitated change. A longer operation time means the prolonged anesthesia and pneumoperitoneum, thus leading to higher risks of cardiorespiratory failures during the operations. There are also authors who believe that the use of the robot even though it facilitates prompter learning of suturing skills, may actually limit the surgeon in training to achieve his/her potential by making him/ her become dependent on the use of the robot for complex tasks [64].

In fact, as far as the author concerned, there is no question that the use of robots in surgery will continue to expand in the future, but long-term studies are still needed to demonstrate the overall equivalent oncologic outcomes, and patients who undergo the operation have to spend high expenditures, as well as the hospitals which introduce the equipment $[44,65]$. In contrast, laparoscopic devices are much simpler and cheaper and are easier to popularize in most hospitals. Beyond that, as a machine, the robot always has the potential of malfunctions, though the rate is very low according to the reports [63]. And this will inevitably increase the insecurity of the operations to a certain extent. Therefore, there is no doubt that it will become an important tool in the surgical armamentarium in the future, but the extent of their use is still evolving. It is not easy to popularize among hospitals and patients at least in the coming future decades. 
There were also reports that concluded different results about LPD. For example, in the report comparing practice patterns and short-term outcomes among 7061 patients, Adam et al. found that the 30-day mortality for patients undergoing MIPD was higher versus OPD, especially during the first phase of the learning curve [66]. In a recent report from Dutch, the clinical trial was even terminated by the data and safety monitoring board because of the more 90-day complication-related deaths associated with LPD [24]. However, as we know, hospital volume and learning curve play important roles in the outcomes of LPD. According to the report of Wang et al., the learning curve of LPD revealed three phases, with proficiency thresholds at 40 and 104 cases, respectively, and long learning curves, low-volume hospitals, and surgical inexperience were associated with higher rates of complications and mortality [67], and Boone et al. revealed similar results in their research [68], while in Adam's study, the majority of hospitals performing MIPD were low volume centers, and in the clinical trial performed in Dutch, institutions, or surgeons that have done 20 or more LPDs can participate in the trial. Therefore, long learning curves, low-volume hospitals, and surgical inexperience may be associated with the higher rates of complications and mortality of LPD in the studies. In addition, two reports from the MD Anderson Cancer Center recently indicated that compared with open abdominal radical hysterectomy, the minimally invasive radical hysterectomy was associated with lower rates of disease-free survival and overall survival among women with early-stage cervical cancer $[69,70]$. All these reports pose challenges to the perioperative and long-term survival outcomes of patients with minimally invasive operations for all malignant tumors including LPD. But we cannot deny previous researches about this issue and the use of minimally invasive techniques, including laparoscopic and robotic, in surgeries because of these reports. These reports should not be the obstacle, but let us become more cautious and rational while moving forward firmly. It should be noted that when we talk about a certain operation, it has not to be completely just one surgery solely. In some cases, in order to maximize the benefits of the surgery, we can combine the above two or more types of surgical methods, that is, the use of hand-assist ports or the hybrid technique. In addition, when finding it is too difficult to continue during the course of LPD or RPD, we should make a conversion to open surgery decisively. Therefore, we must pay attention to the actual situation and combine the different surgical methods reasonably, in order to optimize patient outcomes and mitigate unnecessary healthcare expenditures.

On the opposite, although the application of laparoscopic pancreatic surgery is increasing, we must also note that we should not blindly and complacently go for laparoscopic just for carrying out laparoscopy. In contrast, we should always remember that a competitive desire among surgeons and institutions to implement new minimally invasive techniques is to improve patients' outcomes. Therefore, careful evaluation or assessment for each patient's situation comprehensively is indispensible. And the most suitable operation method should be chosen to maximize the patient's benefits.

For the surgeons, we should establish a better education system to minimize the steep learning curve of LPD. Access to education and training is still the key to popularize this minimally invasive surgical technique [71]. We believe that neither procedure is technically superior to the other, and whether having $\mathrm{R} 0$ resections with an adequate number of lymph nodes harvest largely depends on the technique and experience of the surgeon. Therefore, it is imperative to establish evidence-based guidelines with regard to the determination of competency and standardized training for surgeons with mandated supervision. Otherwise, the rapid introduction of LPD techniques could impair patient's benefits and ultimately the success of the procedure. We should avoid similar mistakes when laparoscopic cholecystectomy was introduced, and some surgeons started performing the operation after only 1 to 3 days of training and without mandated supervision; as a result, there was a high likelihood of bile duct injury sustained among patients [72, 73]. In addition, according to a population-based analysis, risks of postoperative mortality and suboptimal oncologic surgical quality following PD are higher in low volume hospitals than in high volume centers and are more profound with LPD compared with OPD [74]. This reflects the importance of experience based on center volume to perform such complex operations as PD. Therefore, a more specialized and focused large pancreatic center may be more conducive to the development of pancreatic surgery and patients benefit.

Our department is one of the largest pancreatic tumor centers in China. A total of 40 cases of LPD and 50 cases of OPD had been implemented between September 2018 and March 2019; the pathologic characters of the patients include PDAC, ampullary tumor, IPMN, and other neoplasms in both groups. According to the preliminary data, the median length of hospital stay was 11 (9-34) days versus $12(8-48)$ days and the median operation time was 383 (280-580) minutes versus $284(230-470) \mathrm{min}$ in the LPD and OPD group. While the median estimated blood loss was 100 (100-800) $\mathrm{ml}$ in the LPD group, which was significantly less than that in OPD group $(260,100-1200 \mathrm{ml})$ and previous reports, this may be related to the higher proportion of benign or borderline tumors, and the lesions are smaller $(3.0,1.5-7.5 \mathrm{~cm})$ in our cohort. We will continue to expand our cohort and report the experience and outcome of our institution. 
There are some limitations with this review which are mainly related to the quality of available data. The length of hospital stay is not only dependent on the recovery status and severity of postoperative complications, but also depends on the cultural background and medical insurance coverage of the patients in different institutions. Although in most cases, surgeons prefer performing LPD in patients with no comorbidity, no history of abdominal surgery, and no adiposity and benign or borderline neoplasms other than PDAC; almost all studies include all neoplasms mentioned above. There is no consensus on the criteria for patient selection so far. de Rooij et al. had raised a decision-aid algorithm for LPD, but it was based on their own experience and the limited available evidence [75]. Therefore, selection and publication bias unavoidably exists. Many of the studies included relatively a small number of patients, the data is from only a single center, and the follow-up is not very long. All these factors limit the generalizability of the results to some extent.

\section{Conclusions}

To sum up, LPD is safe and feasible. The perioperative and long-term outcomes of LPD are no worse and even superior to OPD and RPD with regard to the length of hospital stay and estimated blood loss. Apart from strict control of indications, standardized training and learning should be guaranteed to ensure safe and stable development of LPD. Moreover, large prospective randomized controlled trials in multiple high volume centers are still needed to further confirm the outcomes. But we believe that the best times for it are coming.

\section{Abbreviations}

IPMN: Intraductal papillary mucinous neoplasm; LPD: Laparoscopic pancreaticoduodenectomy; OPD: Open pancreaticoduodenectomy; PDAC: Pancreatic ductal adenocarcinoma; RPD: Robotic pancreaticoduodenectomy

\section{Acknowledgements}

Not applicable.

\section{Funding}

The present study was supported by National Science Fund for Distinguished Young Scholars [grant number 81625016], National Natural Science Foundation [grant numbers 81502031, 81372651 and 81602085], and Shanghai Sailing Program [grant number 16YF1401800].

\section{Availability of data and materials}

Not applicable.

\section{Authors' contributions}

$\mathrm{ML}$ and SJ contributed equally to this work, collected and analyzed the data, and drafted the manuscript. WX, WL, YQ, QH, QS, and $Z Z$ reviewed and contributed to the revision of the manuscript. $X X$ and $X Y$ designed the study. All authors read and approved the final manuscript.

Ethics approval and consent to participate Not applicable.
Consent for publication

Not applicable.

\section{Competing interests}

The authors declare that they have no competing interests.

\section{Publisher's Note}

Springer Nature remains neutral with regard to jurisdictional claims in published maps and institutional affiliations.

\section{Author details}

${ }^{1}$ Department of Pancreatic Surgery, Fudan University Shanghai Cancer Center, Shanghai 200032, China. ${ }^{2}$ Department of Oncology, Shanghai Medical College, Fudan University, Shanghai 200032, China. ${ }^{3}$ Pancreatic Cancer Institute, Fudan University, Shanghai Pancreatic Cancer Institute, Shanghai 200032, China.

Received: 14 March 2019 Accepted: 1 May 2019

Published online: 10 May 2019

\section{References}

1. Clinical Outcomes of Surgical Therapy Study G, Nelson H, Sargent DJ, Wieand HS, Fleshman J, Anvari M, Stryker SJ, Beart RW Jr, Hellinger M, Flanagan $\mathrm{R} \mathrm{Jr}$, et al. A comparison of laparoscopically assisted and open colectomy for colon cancer. N Engl J Med. 2004:350:2050-9.

2. Ohtani H, Tamamori Y, Noguchi K, Azuma T, Fujimoto S, Oba H, Aoki T, Minami M, Hirakawa K. A meta-analysis of randomized controlled trials that compared laparoscopy-assisted and open distal gastrectomy for early gastric cancer. J Gastrointest Surg. 2010;14:958-64.

3. Vanounou T, Steel JL, Nguyen KT, Tsung A, Marsh JW, Geller DA, Gamblin TC. Comparing the clinical and economic impact of laparoscopic versus open liver resection. Ann Surg Oncol. 2010;17:998-1009.

4. Ishida H, Furukawa Y, Kuroda H, Kobayashi M, Tsuneoka K. Laparoscopic observation and biopsy of the pancrease. Endoscopy. 1981;13:68-73.

5. Ishida H. Peritoneoscopy and pancreas biopsy in the diagnosis of pancreatic diseases. Gastrointest Endosc. 1983;29:211-8.

6. Nassour I, Wang SC, Christie A, Augustine MM, Porembka MR, Yopp AC, Choti MA, Mansour JC, Xie XJ, Polanco PM, Minter RM. Minimally invasive versus open pancreaticoduodenectomy: a propensity-matched study from a national cohort of patients. Ann Surg. 2018;268:151-7.

7. Venkat R, Edil BH, Schulick RD, Lidor AO, Makary MA, Wolfgang CL. Laparoscopic distal pancreatectomy is associated with significantly less overall morbidity compared to the open technique: a systematic review and meta-analysis. Ann Surg. 2012;255:1048-59.

8. Whipple AO, Parsons WB, Mullins CR. Treatment of carcinoma of the ampulla of Vater. Ann Surg. 1935;102:763-79.

9. Gagner M, $\overline{\text { Pomp }}$ A. Laparoscopic pylorus-preserving pancreatoduodenectomy. Surg Endosc. 1994;8:408-10.

10. Palanivelu C, Jani K, Senthilnathan P, Parthasarathi R, Rajapandian S, Madhankumar MV. Laparoscopic pancreaticoduodenectomy: technique and outcomes. J Am Coll Surg. 2007;205:222-30.

11. Gumbs AA, Rodriguez Rivera AM, Milone L, Hoffman JP. Laparoscopic pancreatoduodenectomy: a review of 285 published cases. Ann Surg Oncol. 2011;18:1335-41.

12. Cho A, Yamamoto $H$, Nagata M, Takiguchi $N$, Shimada $H$, Kainuma $O$, Souda H, Gunji H, Miyazaki A, Ikeda A, Tohma T. A totally laparoscopic pyloruspreserving pancreaticoduodenectomy and reconstruction. Surg Today. 2009; 39:359-62.

13. Pugliese R, Scandroglio I, Sansonna F, Maggioni D, Costanzi A, Citterio D, Ferrari GC, Di Lernia S, Magistro C. Laparoscopic pancreaticoduodenectomy: a retrospective review of 19 cases. Surg Laparosc Endosc Percutan Tech. 2008;18:13-8.

14. Torphy RJ, Friedman C, Halpern A, Chapman BC, Ahrendt SS, McCarter MM, Edil BH, Schulick RD, Gleisner A. Comparing short-term and oncologic outcomes of minimally invasive versus open pancreaticoduodenectomy across low and high volume centers. Ann Surg. 2018.

15. Meng LW, Cai YQ, Li YB, Cai H, Peng B. Comparison of laparoscopic and open pancreaticoduodenectomy for the treatment of nonpancreatic periampullary adenocarcinomas. Surg Laparosc Endosc Percutan Tech. 2018; 28:56-61. 
16. Lee CS, Kim EY, You YK, Hong TH. Perioperative outcomes of laparoscopic pancreaticoduodenectomy for benign and borderline malignant periampullary disease compared to open pancreaticoduodenectomy. Langenbecks Arch Surg. 2018;403:591-7.

17. Zhang H, Guo X, Xia J, Zhu F, Shen M, Wang X, Wang M, Qin R. Comparison of totally 3-dimensional laparoscopic pancreaticoduodenectomy and open pancreaticoduodenectomy. Pancreas. 2018;47:592-600

18. Tan CL, Zhang H, Peng B, Li KZ. Outcome and costs of laparoscopic pancreaticoduodenectomy during the initial learning curve vs laparotomy. World J Gastroenterol. 2015;21:5311-9.

19. Delitto D, Luckhurst CM, Black BS, Beck JL, George TJ Jr, Sarosi GA, Thomas RM, Trevino JG, Behrns KE, Hughes SJ. Oncologic and perioperative outcomes following selective application of laparoscopic pancreaticoduodenectomy for periampullary malignancies. J Gastrointest Surg. 2016:20:1343-9.

20. Chapman BC, Gajdos C, Hosokawa P, Henderson W, Paniccia A, Overbey DM, Gleisner A, Schulick RD, McCarter MD, Edil BH. Comparison of laparoscopic to open pancreaticoduodenectomy in elderly patients with pancreatic adenocarcinoma. Surg Endosc. 2018;32:2239-48.

21. Croome KP, Farnell MB, Que FG, Reid-Lombardo KM, Truty MJ, Nagorney DM, Kendrick ML. Total laparoscopic pancreaticoduodenectomy for pancreatic ductal adenocarcinoma: oncologic advantages over open approaches? Ann Surg. 2014;260:633-8 discussion 638-640.

22. Song KB, Kim SC, Hwang DW, Lee JH, Lee DJ, Lee JW, Park KM, Lee YJ. Matched case-control analysis comparing laparoscopic and open pyloruspreserving pancreaticoduodenectomy in patients with periampullary tumors. Ann Surg. 2015;262:146-55.

23. Zureikat AH, Breaux JA, Steel JL, Hughes SJ. Can laparoscopic pancreaticoduodenectomy be safely implemented? J Gastrointest Surg. 2011;15:1151-7.

24. van Hilst J, de Rooij T, Bosscha K, Brinkman DJ, van Dieren S, Dijkgraaf MG, Gerhards MF, de Hingh IH, Karsten TM, Lips DJ, et al. Laparoscopic versus open pancreatoduodenectomy for pancreatic or periampullary tumours (LEOPARD-2): a multicentre, patient-blinded, randomised controlled phase 2/3 trial. Lancet Gastroenterol Hepatol. 2019;4:199-207.

25. Poves I, Burdio F, Morato O, Iglesias M, Radosevic A, Ilzarbe L, Visa L, Grande L. Comparison of perioperative outcomes between laparoscopic and open approach for pancreatoduodenectomy: the PADULAP randomized controlled trial. Ann Surg. 2018;268:731-9.

26. Palanivelu C, Senthilnathan P, Sabnis SC, Babu NS, Srivatsan Gurumurthy S, Anand Vijai N, Nalankilli VP, Praveen Raj P, Parthasarathy R, Rajapandian S. Randomized clinical trial of laparoscopic versus open pancreatoduodenectomy for periampullary tumours. Br J Surg. 2017;104: 1443-50.

27. Chen XM, Sun DL, Zhang Y. Laparoscopic versus open pancreaticoduodenectomy combined with uncinated process approach: a comparative study evaluating perioperative outcomes (retrospective cohort study). Int J Surg. 2018;51:170-3.

28. Zimmerman AM, Roye DG, Charpentier KP. A comparison of outcomes between open, laparoscopic and robotic pancreaticoduodenectomy. HPB (Oxford). 2018:20:364-9.

29. Khaled YS, Fatania K, Barrie J, De Liguori N, Deshpande R, O'Reilly DA, Ammori BJ. Matched case-control comparative study of laparoscopic versus open pancreaticoduodenectomy for malignant lesions. Surg Laparosc Endosc Percutan Tech. 2018;28:47-51.

30. Conrad C, Basso V, Passot G, Zorzi D, Li L, Chen HC, Fuks D, Gayet B. Comparable long-term oncologic outcomes of laparoscopic versus open pancreaticoduodenectomy for adenocarcinoma: a propensity score weighting analysis. Surg Endosc. 2017;31:3970-8.

31. Kantor O, Talamonti MS, Sharpe S, Lutfi W, Winchester DJ, Roggin KK, Bentrem DJ, Prinz RA, Baker MS. Laparoscopic pancreaticoduodenectomy for adenocarcinoma provides short-term oncologic outcomes and longterm overall survival rates similar to those for open pancreaticoduodenectomy. Am J Surg. 2017;213:512-5.

32. Stauffer JA, Coppola A, Villacreses D, Mody K, Johnson E, Li Z, Asbun HJ. Laparoscopic versus open pancreaticoduodenectomy for pancreatic adenocarcinoma: long-term results at a single institution. Surg Endosc. 2017; 31:2233-41.

33. Sharpe SM, Talamonti MS, Wang CE, Prinz RA, Roggin KK, Bentrem DJ, Winchester DJ, Marsh RD, Stocker SJ, Baker MS. Early national experience with laparoscopic pancreaticoduodenectomy for ductal adenocarcinoma: a comparison of laparoscopic pancreaticoduodenectomy and open pancreaticoduodenectomy from the National Cancer Database. J Am Coll Surg. 2015;221:175-84

34. Hakeem AR, Verbeke CS, Cairns A, Aldouri A, Smith AM, Menon KV. A matched-pair analysis of laparoscopic versus open pancreaticoduodenectomy: oncological outcomes using Leeds Pathology Protocol. Hepatobiliary Pancreat Dis Int. 2014;13:435-41.

35. Langan RC, Graham JA, Chin AB, Rubinstein AJ, Oza K, Nusbaum JA, Smirniotopoulos J, Kayser R, Jha R, Haddad N, et al. Laparoscopic-assisted versus open pancreaticoduodenectomy: early favorable physical quality-oflife measures. Surgery. 2014;156:379-84.

36. Asbun HJ, Stauffer JA. Laparoscopic vs open pancreaticoduodenectomy: overall outcomes and severity of complications using the Accordion Severity Grading System. J Am Coll Surg. 2012;215:810-9.

37. Gala RB, Margulies R, Steinberg A, Murphy M, Lukban J, Jeppson P, Aschkenazi S, Olivera C, South M, Lowenstein L, et al. Systematic review of robotic surgery in gynecology: robotic techniques compared with laparoscopy and laparotomy. J Minim Invasive Gynecol. 2014;21:353-61.

38. Berber E. Robotic general surgery: the current status and a look into the future. J Surg Oncol. 2015;112:239.

39. Giulianotti PC, Sbrana F, Bianco FM, Elli EF, Shah G, Addeo P, Caravaglios G, Coratti A. Robot-assisted laparoscopic pancreatic surgery: single-surgeon experience. Surg Endosc. 2010;24:1646-57.

40. Nguyen KT, Zureikat AH, Chalikonda S, Bartlett DL, Moser AJ, Zeh HJ. Technical aspects of robotic-assisted pancreaticoduodenectomy (RAPD). J Gastrointest Surg. 2011;15:870-5.

41. Zureikat AH, Moser AJ, Boone BA, Bartlett DL, Zenati M, Zeh HJ 3rd. 250 robotic pancreatic resections: safety and feasibility. Ann Surg. 2013;258:5549 discussion 559-562.

42. Zhou NX, Chen JZ, Liu Q, Zhang X, Wang Z, Ren S, Chen XF. Outcomes of pancreatoduodenectomy with robotic surgery versus open surgery. Int J Med Robot. 2011;7:131-7.

43. Zeh HJ, Zureikat AH, Secrest A, Dauoudi M, Bartlett D, Moser AJ. Outcomes after robot-assisted pancreaticoduodenectomy for periampullary lesions. Ann Surg Oncol. 2012;19:864-70.

44. Boggi U, Signori S, De Lio N, Perrone VG, Vistoli F, Belluomini M, Cappelli C, Amorese G, Mosca F. Feasibility of robotic pancreaticoduodenectomy. Br J Surg. 2013;100:917-25

45. Magge D, Zenati M, Lutfi W, Hamad A, Zureikat AH, Zeh HJ, Hogg ME. Robotic pancreatoduodenectomy at an experienced institution is not associated with an increased risk of post-pancreatic hemorrhage. HPB (Oxford). 2018;20:448-55.

46. de Rooij T, Lu MZ, Steen MW, Gerhards MF, Dijkgraaf MG, Busch OR, Lips DJ, Festen S, Besselink MG, Dutch Pancreatic Cancer G. Minimally invasive versus open pancreatoduodenectomy: systematic review and meta-analysis of comparative cohort and registry studies. Ann Surg. 2016:264:257-67.

47. Zhang Y, Hong D, Zhang C, Hu Z. Total laparoscopic versus robot-assisted laparoscopic pancreaticoduodenectomy. Biosci Trends. 2018;12:484-90.

48. Liu R, Zhang T, Zhao ZM, Tan XL, Zhao GD, Zhang X, Xu Y. The surgical outcomes of robot-assisted laparoscopic pancreaticoduodenectomy versus laparoscopic pancreaticoduodenectomy for periampullary neoplasms: a comparative study of a single center. Surg Endosc. 2017:31:2380-6.

49. Nassour I, Choti MA, Porembka MR, Yopp AC, Wang SC, Polanco PM. Robotic-assisted versus laparoscopic pancreaticoduodenectomy: oncological outcomes. Surg Endosc. 2018;32:2907-13.

50. Buchs NC, Addeo P, Bianco FM, Ayloo S, Benedetti E, Giulianotti PC. Robotic versus open pancreaticoduodenectomy: a comparative study at a single institution. World J Surg. 2011;35:2739-46.

51. Zhang J, Wu WM, You L, Zhao YP. Robotic versus open pancreatectomy: a systematic review and meta-analysis. Ann Surg Oncol. 2013;20:1774-80.

52. Chen S, Chen JZ, Zhan Q, Deng XX, Shen BY, Peng CH, Li HW. Robotassisted laparoscopic versus open pancreaticoduodenectomy: a prospective, matched, mid-term follow-up study. Surg Endosc. 2015;29: 3698-711.

53. Bao PQ, Mazirka PO, Watkins KT. Retrospective comparison of robot-assisted minimally invasive versus open pancreaticoduodenectomy for periampullary neoplasms. J Gastrointest Surg. 2014;18:682-9.

54. Pedziwiatr M, Malczak P, Pisarska M, Major P, Wysocki M, Stefura T, Budzynski A. Minimally invasive versus open pancreatoduodenectomy-systematic review and meta-analysis. Langenbecks Arch Surg. 2017;402:841-51. 
55. Biagi JJ, Raphael MJ, Mackillop WJ, Kong W, King WD, Booth CM. Association between time to initiation of adjuvant chemotherapy and survival in colorectal cancer: a systematic review and meta-analysis. JAMA. 2011:305:2335-42.

56. Hofstetter G, Concin N, Braicu I, Chekerov R, Sehouli J, Cadron I, Van Gorp T, Trillsch F, Mahner S, Ulmer $\mathrm{H}$, et al. The time interval from surgery to start of chemotherapy significantly impacts prognosis in patients with advanced serous ovarian carcinoma - analysis of patient data in the prospective OVCAD study. Gynecol Oncol. 2013;131:15-20.

57. Reeh M, Ghadban T, Dedow J, Vettorazzi E, Uzunoglu FG, Nentwich M, Kluge S, Izbicki JR, Vashist YK. Allogenic blood transfusion is associated with poor perioperative and long-term outcome in esophageal cancer. World J Surg. 2017:41:208-15.

58. Veenhof AA, Sietses C, von Blomberg BM, van Hoogstraten IM, vd Pas MH, Meijerink WJ, vd Peet DL, vd Tol MP, Bonjer HJ, Cuesta MA. The surgical stress response and postoperative immune function after laparoscopic or conventional total mesorectal excision in rectal cancer: a randomized trial. Int J Colorectal Dis. 2011;26:53-9.

59. Mahajan UM, Langhoff E, Goni E, Costello E, Greenhalf W, Halloran C, Ormanns S, Kruger S, Boeck S, Ribback S, et al. Immune cell and stromal signature associated with progression-free survival of patients with resected pancreatic ductal adenocarcinoma. Gastroenterology. 2018:155:1625-1639 e1622.

60. Wang $H$, Wang $Y$, Xing $H$, Zhou $Y$, Zhao J, Jiang J, Liu Q. Laparoscopic Surgery Within an Enhanced Recovery after Surgery (ERAS) protocol reduced postoperative ileus by increasing postoperative Treg levels in patients with right-side colon carcinoma. Med Sci Monit. 2018;24:7231-7.

61. Gerber MH, Delitto D, Crippen CJ, George TJ Jr, Behrns KE, Trevino JG, Cioffi $J \mathrm{~L}$, Hughes SJ. Analysis of the cost effectiveness of laparoscopic pancreatoduodenectomy. J Gastrointest Surg. 2017;21:1404-10.

62. Tran TB, Dua MM, Worhunsky DJ, Poultsides GA, Norton JA, Visser BC. The first decade of laparoscopic pancreaticoduodenectomy in the United States: costs and outcomes using the nationwide inpatient sample. Surg Endosc. 2016;30:1778-83.

63. Giulianotti PC, Coratti A, Angelini M, Sbrana F, Cecconi S, Balestracci T, Caravaglios G. Robotics in general surgery: personal experience in a large community hospital. Arch Surg. 2003;138:777-84.

64. Mesleh MG, Stauffer JA, Asbun HJ. Minimally invasive surgical techniques for pancreatic cancer: ready for prime time? J Hepatobiliary Pancreat Sci. 2013; 20:578-82.

65. Horiguchi A, Uyama I, Miyakawa S. Robot-assisted laparoscopic pancreaticoduodenectomy. J Hepatobiliary Pancreat Sci. 2011;18:287-91.

66. Adam MA, Choudhury K, Dinan MA, Reed SD, Scheri RP, Blazer DG 3rd, Roman SA, Sosa JA. Minimally invasive versus open pancreaticoduodenectomy for cancer: practice patterns and short-term outcomes among 7061 patients. Ann Surg. 2015;262:372-7.

67. Wang M, Peng B, Liu J, Yin X, Tan Z, Liu R, Hong D, Zhao W, Wu H, Chen R, et al. Practice patterns and perioperative outcomes of laparoscopic pancreaticoduodenectomy in China: a retrospective multicenter analysis of 1029 patients. Ann Surg. 2019.

68. Boone BA, Zenati M, Hogg ME, Steve J, Moser AJ, Bartlett DL, Zeh HJ, Zureikat AH. Assessment of quality outcomes for robotic pancreaticoduodenectomy: identification of the learning curve. JAMA Surg. 2015;150:416-22.

69. Ramirez PT, Frumovitz M, Pareja R, Lopez A, Vieira M, Ribeiro R, Buda A, Yan $X$, Shuzhong $Y$, Chetty $N$, et al. Minimally invasive versus abdominal radical hysterectomy for cervical cancer. N Engl J Med. 2018;379:1895-904.

70. Melamed A, Margul DJ, Chen L, Keating NL, Del Carmen MG, Yang J, Seagle $\mathrm{BL}$, Alexander A, Barber EL, Rice LW, et al. Survival after minimally invasive radical hysterectomy for early-stage cervical cancer. N Engl J Med. 2018;379: 1905-14.

71. de Rooij T, van Hilst J, Topal B, Bosscha K, Brinkman DJ, Gerhards MF, de Hingh $\mathrm{IH}$, Karsten TM, Lips DJ, Luyer MD, et al. Outcomes of a multicenter training program in laparoscopic pancreatoduodenectomy (LAELAPS-2). Ann Surg. 2019;269:344-50.

72. Archer SB, Brown DW, Smith CD, Branum GD, Hunter JG. Bile duct injury during laparoscopic cholecystectomy: results of a national survey. Ann Surg. 2001;234:549-58 discussion 558-549.

73. A prospective analysis of 1518 laparoscopic cholecystectomies. The Southern Surgeons Club. N Engl J Med. 1991;324:1073-8.
74. Kutlu OC, Lee JE, Katz MH, Tzeng CD, Wolff RA, Varadhachary GR, Vauthey JN, Fleming JB, Conrad C. Open pancreaticoduodenectomy case volume predicts outcome of laparoscopic approach: a population-based analysis. Ann Surg. 2018;267:552-60.

75. de Rooij T, Klompmaker S, Abu Hilal M, Kendrick ML, Busch OR, Besselink MG. Laparoscopic pancreatic surgery for benign and malignant disease. Nat Rev Gastroenterol Hepatol. 2016;13:227-38.

\section{Ready to submit your research? Choose BMC and benefit from:}

- fast, convenient online submission

- thorough peer review by experienced researchers in your field

- rapid publication on acceptance

- support for research data, including large and complex data types

- gold Open Access which fosters wider collaboration and increased citations

- maximum visibility for your research: over $100 \mathrm{M}$ website views per year

At BMC, research is always in progress.

Learn more biomedcentral.com/submissions 